\title{
Saberes e práticas médicas e a constituição da identidade pessoal
}

CLARA VIRGINIA DE Q. PINHEIRO*

\section{RESUMO}

O objetivo deste artigo é examinar a relação entre práticas de saúde e a constituição da identidade pessoal. Nosso ponto de partida é a tese foucaultiana de que a medicina moderna inaugura um campo de conhecimento científico sobre o corpo, tendo em vista sua objetivação a partir da referência à morte. O lugar central do corpo no domínio médico possibilita uma forma de relação do sujeito consigo mesmo na qual a consciência de si como singularidade, ou seja, como eu mesmo, se confunde com a individualidade orgânica. Pressupomos que no contexto da clínica a formação da identidade se caracteriza pelo fato de estar circunscrita aos limites da corporeidade. Entretanto, na atualidade, com a biomedicina, o corpo se torna objeto de manipulação do indivíduo, transformando a relação de identidade entre subjetividade e corporeidade. Desencarnada, a identidade pessoal se torna realidade freneticamente mutante.

Palavras-chave: Práticas de saúde, identidade pessoal e corporeidade, Michel Foucault.

Recebido em: 10/02/2006.

Aprovado em: 11/06/2006. 
O objetivo do presente artigo é examinar a relação entre os saberes e práticas de saúde e a constituição de certa forma de experiência de si. Partimos da seguinte idéia: o campo médico, mais do que um domínio estritamente técnicocientífico, estabelece parâmetros através dos quais o indivíduo define sua identidade pessoal. Em outros termos, a experiência médica implica, de um lado, teorias e procedimentos técnicos e, de outro lado, um indivíduo que se posiciona como objeto desse saber, na medida que se reconhece como doente, uma vez que sofre de um mal orgânico.

Nesse contexto, devemos ressaltar o lugar central do corpo, que constitui, para lançar mão de indicações de Ricoeur (1987), o ponto de ancoragem do sujeito, o qual o inscreve no mundo, situando-o como singularidade, ou seja, como eu mesmo. O corpo como referência da experiência subjetiva se relaciona ao fato de a existência pessoal ser compreendida a partir das formas temporal e espacial de estar no mundo, isto é, como ser vivo. Assim, essa maneira de se situar no mundo implica abandonar a idéia de que a doença é algo que existe em si mesmo, que constitui realidade própria, independentemente de uma inscrição corporal. Implica, ainda, descartar a crença de que a razão do mal se explica por uma vontade divina.

Nessa abordagem das relações entre práticas de saúde e identidade pessoal, seguimos a linha de pensamento foucaultiano acerca dos processos pelos quais o homem se torna sujeito. Foucault (1994c) considera dois sentidos relativos à noção de sujeito, quais sejam, sujeito no que diz respeito a estar submetido ao outro e sujeito ligado à própria identidade, pela consciência ou conhecimento de si mesmo. Com relação ao sentido de sujeito subordinado à própria identidade, Foucault (1994c) formula a idéia de um trabalho de autoformação através do qual o sujeito se reconhece como objeto de um saber e de uma prática científica, bem como sujeito de uma determinada cultura. Portanto, não devemos pensar que na nossa sociedade medicalizada o indivíduo é passivamente arrastado a uma condição de mero objeto científico.

Dessa forma devemos ressaltar, em conformidade com os ensinamentos de Foucault, que é em referência ao universo simbólico, o qual implica saberes, poderes e técnicas de constituição de si, que situamos nossa problemática. Tratase, então, como nos esclarece Kehl (2003, p. 243), de examinar a experiência do eu e do corpo como objetos sociais, distanciando-se, pelo menos nos limites do presente trabalho, de uma referência à dimensão subjetiva da corporeidade na direção de uma fenomenologia da corporeidade, como fez Ortega (2005a, 
2005b) em seus estudos sobre os efeitos das novas tecnologias na experiência subjetiva do corpo.

Foi na esteira dessa concepção que abordamos o livro Nascimento da clínica, no qual Foucault (1994a) estuda as condições de possibilidade dos discursos médico-científicos. Podemos dizer, a partir dessa pesquisa foucaultiana, que com a medicina moderna se inaugura uma forma de ser sujeito como algo que diz respeito à individualidade corporal. Pois, como afirma Siding (1992), devemos reconhecer o mesmo denominador comum nos estudos foucaultianos sobre a loucura, a morte e a doença na modernidade - por exemplo, a constituição de uma forma de relação consigo mesmo como indivíduo, logo, o reconhecimento de si mesmo como fundamento de toda e qualquer experiência.

Nossa hipótese é de que com a medicina moderna inaugura-se um novo campo da experiência subjetiva no qual a identidade pessoal está intrinsecamente relacionada ao corpo, que, por sua vez, é entendido a partir das noções de vida e morte. Em outros termos, a clínica moderna se estabelece pela ruptura com a visão dualista entre mente e corpo, engendrando uma forma de experiência subjetiva enraizada na existência corporal, isto é, nas sensações e nas necessidades de sobrevivência e, também, nas vivências de prazer e desprazer.

Ora, podemos supor que a perspectiva médica característica da modernidade origina uma forma de subjetividade sobreposta à corporeidade, referindo-se ao sentir, ao ter prazer e ao desejar - quer dizer, precisamente, ao estar vivo, tendo em vista a posição singular relativa à morte. Daí a dificuldade de desvincular a identidade pessoal, ou seja, o eu mesmo, do corporal como se fossem realidades diferentes. Pois a experiência de estar vivo implica a simultaneidade da referência ao corporal e ao subjetivo, uma vez que constitui, conforme indicações de Ricouer (1987, p. 76-77) "um fato de inscrição, a saber, a inscrição do tempo vivido no tempo do mundo. Da mesma maneira, a conexão entre aqui e um lugar do mundo, a localização, é também um fato de inscrição". A corporeidade demarca, assim, a posição do particular, do individual, em relação ao geral, ao universal. Talvez não seja incorreto afirmar que essa forma de inscrição do indivíduo no mundo, situando-o como ser finito, constitui, propriamente, o objeto dos discursos clínicos característicos da medicina anatomopatológica.

Todavia, devemos entrever relações diferentes entre a identidade pessoal e a forma de corporeidade na medida em que os discursos científicos se deslocam 
de uma anatomopatologia para uma biomedicina (e biotecnologias). Tal transferência discursiva implica mudanças de paradigmas no que diz respeito à corporeidade, a qual deixa de ser referida à finitude, constituindo-se em matériaprima da normatividade biológica. Essa mudança de modelos médicos implica a desencarnação da subjetividade, uma vez que, nos novos discursos, o corpo deixa de ser o ponto de ancoragem do sujeito no mundo, pois perde a referência às dimensões temporal e espacial, que têm como referente a vida em relação intrínseca com a morte. Assim, ressaltamos mais uma vez que situamos nossas problemáticas da corporeidade e da identidade pessoal tendo em vista as redes discursivas que implicam relações de forças e nas quais se redefinem as posições de corpo/mente, identidade/alteridade, natureza/cultura, homem/máquina.

Situemo-nos, então, no interior dos discursos e práticas médicas.

\section{O surgimento da medicina moderna e a constituição da experiência subjetiva da corporeidade}

Segundo Machado (1982), Nascimento da clínica trata especificamente da história da ruptura conceitual da ciência médica, entre uma medicina classificatória das espécies patológicas do século XVII e a inauguração de um saber médico do indivíduo doente, que tem início no final do século XVIII. Através dessa ruptura se constitui uma nova concepção de doença como lesão corporal, radicalizando-se como novo campo epistemológico, com a anatomopatologia estabelecida por Bichat, que torna possível uma medicina fisiológica, com Brossais.

Decerto, neste estudo sobre a medicina podemos dar ênfase à constituição de uma forma de subjetividade como realidade concreta, que se refere à experiência da corporeidade. Partimos da idéia de que os saberes médicos e biológicos característicos da época moderna inventam uma sobreposição entre individualidade orgânica e subjetividade. Acreditamos, então, que a história do nascimento da clínica trata da gênese de uma forma de consciência de si, ao mesmo tempo em que instaura novo campo do conhecimento científico.

Segundo Foucault (1994a), a clínica é um campo do conhecimento médico no qual a doença é identificada a uma lesão corporal. Tal forma de definição da doença implica o rompimento com a medicina classificatória, dominante no século XVII e meados do século XVIII, que concebia as doenças como essências patológicas, definidas como configuração de sintomas. 
O novo campo epistemológico, de acordo com Foucault (1994a), se instaura a partir das pesquisas de Bichat sobre os tecidos como elementos constitutivos da unidade corporal, como fundamento dos fenômenos orgânicos. Daí se estabelecer uma relação entre anatomia e patologia, entre corpo e doença. $\mathrm{Na}$ medida em que a doença passa a ser referida ao corpo, os sintomas deixam de ser considerados a própria doença. Todas as alterações da experiência, como febres, sensação de asfixia, palpitações súbitas, por exemplo, não constituem em si mesmas os fenômenos da doença, mas se referem às condições e às lesões tissulares, construindo um sistema de relações que diz respeito a causas, origens e sedes. A partir da anatomopatologia, todo sintoma clínico deve ser relacionado a uma alteração morfológica. Nas palavras de Foucault (1994a, p. 155):

A doença não é um feixe de características disseminadas pela superfície do corpo [...] é um conjunto de formas e deformações, figuras, acidentes, elementos deslocados, destruídos ou modificados que se encadeiam uns com os outros, segundo uma geografia que se pode seguir passo a passo. Não é mais uma espécie patológica inserindo-se no corpo, onde é possível; é o próprio corpo tornando-se doente.

É a referência à morte que promove a descontinuidade entre a medicina clássica e a medicina moderna, uma vez que referida à morte a doença perde $\mathrm{o}$ estatuto de realidade originária e essencial. Assim, a descoberta do corpo como espaço próprio da doença está estreitamente ligada às noções biológicas de vida e morte. Pois, como ressalta Foucault (1994a, p. 227), somente a partir da formulação da morte como fundamento epistemológico do fenômeno patológico que a doença pôde "tomar corpo no corpo vivo dos indivíduos" (grifos do autor).

Com efeito, essa relação fundamental entre corpo, vida e morte está vinculada tanto às pesquisas de Bichat, acerca dos tecidos como elementos constitutivos da unidade corporal, como, segundo o ponto de vista de Foucault (1995), a Cuvier. Este efetuou uma reorganização no saber biológico, através da qual subordina a análise dos seres vivos à estrutura orgânica, a qual se define por referência à funcionalidade. Pois a biologia está ligada à formulação da noção de vida, entendida como puro movimento, na medida em que tem como propriedade essencial a função. Referida à função, a vida é movimento em direção às condições de manutenção e realização da existência. Com a função como referência, o corpo constitui uma totalidade organizada na qual as 
partes se relacionam de forma dependente, não havendo modificação num elemento que não altere todo o sistema. Portanto, há um entrecruzamento entre os conceitos de vida, corpo, doença e morte. O conceito de vida só pode se esclarecer na medida em que se considera sua situação de oposição à morte. Nessa perspectiva, devemos reconhecer a enorme influência de Canguilhem (1995), em suas pesquisas sobre as relações entre normal e patológico, sobre os estudos foucaltianos acerca do surgimento das ciências modernas.

Nesse contexto epistemológico, vida e morte adquirem um estatuto eminentemente instrumental, uma vez que dizem respeito ao funcionamento do corpo e suas condições de existência. Nesse sentido, a morte é um fato preciso e localizável no corpo, seja como fenômeno que diz respeito à falência dos órgãos ou, segundo o conceito mais recente, morte encefálica. Morrer significa não gozar fisicamente das coisas boas da vida; assim, diz respeito à ausência ou ineficiência da atividade corporal. Dessa maneira, a morte não confere nenhuma dignidade ao sujeito, como cita Vernant (1987), no período arcaico, no qual a bela morte perpetuava gloriosamente os nomes dos heróis guerreiros.

Desse modo, tendo em vista os ensinamentos de Canguilhem (1995), temos de um lado os movimentos da vida, que se caracterizam pelo estabelecimento das condições de sua manutenção e realização e, de outro, os movimentos que conduzem à destruição orgânica. A partir desse ponto de vista da normatividade da vida, a doença significa forma de vida inadequada, desvalorizada, exprime um modo de realização deficiente da vida.

Quanto à oposição entre vida e morte, a doença adquire seu significado, assumindo uma posição intermediária, pois se constitui como uma forma de vida patológica. Em outras palavras, a vida, a doença e a morte são fenômenos localizáveis e visíveis no corpo, cujo princípio de funcionamento é a polaridade da vida e da morte. A vida é entendida como normatividade, isto é, criação de normas de vida, enquanto a doença se define como limitação, impossibilidade, impotência do organismo em relação às necessidades de funcionalidade - portanto, de sobrevivência.

Ora, essa concepção médica e biológica da vida, da morte e da doença como realidade corporal cria uma forma de relação do homem consigo mesmo. Podemos dizer que a problemática da doença, da vida e da morte só pode ser qualificada quando se leva em conta a individualidade orgânica de cada ser vivo. A medida da normatividade, ou seja, capacidade de resistência à morte, é relativa à forma de vida de cada um e às condições do funcionamento orgânico 
frente às exigências do meio. Nesse sentido, o objeto do saber e da intervenção médica é a existência de cada indivíduo. Em outros termos, a forma de vida só pode ser qualificada tendo em vista que cada caso é um caso. Portanto, o corpo de cada um se torna não só meio de sobrevivência, mas, fundamentalmente, o princípio e o fim da própria existência, na medida em que se sobrepõem corpo saudável e formas adequadas de viver - de querer e ter prazer e de ser livre. Portanto, queremos ressaltar que a experiência de si como sujeito está intrinsecamente subordinada à experiência do corpo como realidade temporal e espacial, i.e., como finitude.

Esse caráter individualizante do cuidado médico obriga o sujeito a uma preocupação permanente com a própria saúde, a qual depende de sua forma de vida. Estabelece, assim, uma prática de auto-regulação, autodomínio que implica o conhecimento de sua situação orgânica singular. Daí o individuo submeter-se, incessantemente, a uma disciplina constante da alimentação, da higiene, dos exercícios físicos, das relações sexuais, entre outros cuidados.

Conforme a perspectiva foucaultiana, a especificidade da medicina moderna é a constituição da individualidade - portanto, da conduta individual, como objeto da atenção médica. Nesse ponto, inspirando-se em Pinell (1998), podemos reconhecer o papel das práticas médicas no processo civilizador, tal como foi tratado por Norberto Elias (1994), possibilitando a generalização e a consolidação das mudanças de costumes no que diz respeito aos cuidados corporais, às boas maneiras que passam a regular as relações entre os homens nas sociedades ocidentais modernas.

Os comportamentos civilizados com os quais estamos acostumados, tais como os hábitos de usar o banheiro para funções corporais e os cuidados higiênicos, como escarrar, limpar o nariz, como também a disciplina à mesa de não comer com as mãos, resultaram de um longo processo de constituição do autocontrole corporal. Hoje, esses comportamentos são justificados mais pelos cuidados com a saúde do que pelas boas maneiras necessárias à convivência social à qual foram associadas originariamente na sociedade de corte. Desse modo, o cuidado com o corpo não se justifica pelas relações entre os homens, por uma preocupação com a vida em sociedade, mas com a inquietação em relação a si mesmo, à maneira própria de estar no mundo, que se qualifica pelas possibilidades de uma vida saudável e durável. A vida, como realidade corporal, tornou-se a razão de ser absoluta da nossa disciplina, de nossa submissão às regras e interdições. 
Portanto, não incorreremos em erro ao enfatizar que com a racionalidade anatomopatológica se estabelece uma relação de dependência entre identidade pessoal e corporeidade. A identidade está circunscrita aos limites corporais, não sendo possível extrapolá-los. O corpo encarna o destino inexorável da existência humana. Entretanto, o homem pode evitar a doença e, conseqüentemente, a morte, através do adestramento de seus hábitos e comportamentos, instaurando, assim, uma prática permanente de autocontrole. Tal prática de cuidado de si implica um reconhecimento de si como sujeito autônomo e responsável que pode, a partir de decisões corretas (saudáveis), definir o curso de seu destino tendo em vista seus limites físicos que o singularizam e o situam entre a vida e a morte. Desse modo, podemos dizer que essa sobreposição da corporeidade e da subjetividade constitui uma experiência que se caracteriza pela temporalidade (passado, presente, futuro, duração, continuidade) e espacialidade (direcionamento, orientação, adaptabilidade), a partir das quais o sujeito se define como singularidade, como si mesmo.

Consideramos que a ênfase dada às possibilidades da vida como realidade em si mesma - descartando a referência à morte, que caracteriza as biomedicinas - acarreta uma mudança na relação entre corporeidade e subjetividade, na medida em que a irredutibilidade corporal deixa de ser a matéria-prima do trabalho de constituição de si como sujeito. Talvez não seja incorreto dizer que a biomedicina transforma a relação de identidade entre o corporal e o si mesmo, uma vez que os discursos médicos deixam de se referir à morte como fundamento do vivo, engendrando, de acordo com Tucherman (2004, p. 192), "outras experiências espaço-temporais, outras subjetividades, inteligências e mesmo anatomias".

\section{A biomedicina e a objetivação do corpo}

Assim, o domínio propriamente clínico das práticas de saúde fundadas pela anatomia patológica, organizadas em torno da idéia de corpo doente a partir da oposição entre vida e morte, está sendo suplantado por um domínio que abandona o pólo da morte como referência. Esta se orienta pela concepção de vida como realidade que se define por si mesma, que deve ser o alvo para o qual convergem todos os esforços médicos. Agora o objeto das novas formas de intervenções médicas deixa de ser o corpo padecente do sujeito, mas as possibilidades ilimitadas de qualificação e potencialização das formas de vida. Ora, ao mesmo tempo em que se inaugura um novo campo médico, se estabelecem novas relações entre identidade e corporeidade. 
A medicina, quando ultrapassa seus limites propriamente clínicos, estendendo seu domínio de objetos para além do corpo doente, está também ampliando suas funções com finalidades essencialmente terapêuticas, de normalização do indivíduo para a função de prevenção e, mais precisamente, de promoção de saúde. Daí a importância considerável que a medicina genética tem hoje, viabilizada pela racionalidade da biologia molecular, em função de seu caráter eminentemente preditivo e preventivo, de detectar, antes mesmo de o indivíduo ter nascido, suas predisposições à doença. Nesse contexto, conforme indicações de Le Breton (2003), o cadáver - mais precisamente, a morte deixa de ser o fundamento epistemológico do conhecimento sobre a vida.

Trata-se, então, a propósito de um saber e de uma prática de qualificação da vida, da constituição de outro campo médico, no qual a experiência do sujeito não se baseia na oposição entre o normal e o patológico, nem implica uma experiência corporal, tal como se realiza na clínica. Agora, conforme indicações de Sinding (1992, p. 80), a biologia, um saber sobre a vida e não sobre a doença (talvez seja interessante explicitar), tomou conta da configuração sobre as condições médicas do indivíduo, que não se fundamenta no exame ocular da anatomia, "o signo biológico não tem nada de visual". Podemos dizer, juntamente com Sinding, que a medicina, mais do que uma ciência do normal e do patológico, é hoje uma ciência do "devir do indivíduo. Uma medicina dita preditiva visa a impedir que a doença se atualize." A partir da perspectiva da medicina biológica, a individualidade não diz respeito à organicidade do corpo, mas, segundo Reid (1992, p. 121), à "sua programação por seqüências genéticas". Desse modo, a atividade monótona, cotidiana, do olhar médico sobre a singularidade do corpo doente, é substituída pela leitura de uma configuração genética codificada, que, podemos dizer, não tem nada de pessoal. Com isso, a relação médico-paciente deixa de ser o cerne da prática médica. Com sua estrutura de genes codificada, é possível - este é o sonho de muitos geneticistas - que cada indivíduo possa ter seu genoma particular, que poderá vir transcrito num compact disc (REID, 1992). Tal objeto deterá o segredo, se segredo houver, de cada individualidade, que, enfatizamos, não tem nada de singular e de pessoal. É preciso, então, que perguntemos: de que tipo de subjetividade se trata nesse campo da biomedicina?

É importante lembrar que, conforme vimos acerca da anatomia patológica, a prática clínica cria uma experiência da individualidade, podemos dizer, da pessoalidade, intrinsecamente relacionada à opacidade do corpo. $\mathrm{O}$ exame detalhado que olha, perscruta, palpa e escuta o corpo possibilita um forte sentido de identidade, na medida em que associa à referência ao eu mesmo, 
ao corpo, tendo em vista seu tempo vivido. E agora, cabe-nos perguntar: o que está em jogo a propósito do corpo e do sujeito nessas novas práticas, discursos e instituições médico-científicos que partem dos genes como referência última dos seres vivos? Podemos pensar que é esse o pano de fundo da crescente sensação de perplexidade e de novidade com relação às implicações das pesquisas biológicas em esferas não somente científicas, mas, também, nos domínios legais, médicos, artísticos e morais.

Do ponto de vista teórico, Reid (1992), seguindo a linha de análise foucaultiana, estabelece comparações entre clínica e medicina genética, procurando as bases de uma reorganização do saber sobre a doença. $\mathrm{O}$ alvo dos deslocamentos entre uma e outra, entre anatomopatologia e biologia molecular, se concentra na individualidade orgânica, uma vez que na genética se substitui a dependência entre doença e movimento funcional pela programação linear dos genes, independentemente de um organismo. Mesmo considerando que há controvérsias entre os cientistas biológicos a esse respeito, Reid se refere à posição de François Jacob sobre o método de análise próprio dos geneticistas, que aponta para o longo percurso entre genótipo e fenótipo, que é desconhecido, podendo haver alguma solidariedade orgânica em relação à expressão de determinado gene. No entanto, a genética se interessa pelo que aparece na superfície e, daí, procura deduzir o conteúdo.

Assim Reid (1992, p. 123) cita Jacob, biólogo, ganhador do Prêmio Nobel (1965, com Lwof e Monod): "Quanto aos mecanismos intermediários que vão do gene ao caráter, a genética os ignora totalmente”. Em outros termos, a partir dessa concepção, a genética não se interessa pelo indivíduo, não quer saber das interações do gene com o meio orgânico. Por outro lado, Reid (1992, p. 124) também aponta para pesquisas que procuram conhecer os modos de intervenção dos genes sobre o funcionamento orgânico: "Fala-se mais e mais de uma genética 'fisiologista' individualizante, na medida em que a ausência ou presença de um gene pode em alguns deslanchar uma doença e em outros não produzir nada". Mas não se pode confundir aí, pois, como afirma Reid, alguma coisa nos leva para além da clínica, que é a prática de manipulação do material genético, ou seja, a intervenção nos códigos genéticos com o objetivo de transformá-los, de criar possibilidades, de ir além das identidades. É como, por exemplo, grosseiramente falando, fazer um cajueiro produzir bananas, como também produzir gerações de indivíduos idênticos, sem variações genéticas, que é o caso das técnicas de clonagem. Nessas práticas, a dependência entre identidade, individualidade e corpo se perde. 
Podemos pensar numa paixão pela mutação que pode ser expressa pela questão: "se posso mudar, por que continuar o mesmo?". Podemos pensar, de acordo com Le Breton (2004), numa nova versão do dualismo, que se estabelece a partir de uma relação de exterioridade entre homem e corpo, mas não mais nos termos de uma dualidade entre mente e corpo. É, segundo Foucault (1995), ultrapassar os limites da finitude, assim como analisa Deleuze (1986). Trata-se do fini-ilimitado, de partir dos códigos dados e levar as possibilidades ilimitadas de situações novas, chegando ao desaparecimento definitivo da idéia de homem. Como reforça Reid (1992, p. 126): “a transplantação do gene - dos códigos - embaralha a linha de demarcação entre o humano e o animal e mesmo entre o animado e inanimado".

Tais mudanças no estatuto do real e do humano, a partir dos discursos científicos, constituem temas de vários estudos, que abordam diferentes aspectos da constituição de uma nova antropologia. Para citar apenas alguns, Le Breton (2003), considerando as várias tecnologias que marcam o mundo contemporâneo, fala da desencarnação da alma em virtude da desvalorização do corpo como meio de realização da condição humana; Jurandir Freire Costa (2004) examina a personalidade somática como resultado da reviravolta do mundo dos valores, as normas científicas tomam o lugar dos ideais morais, engendrando as bioidentidades; Haraway (1985) e Tucherman (2004) apontam a ruptura com a modernidade instaurada pelas novas práticas médicas, conduzindo à morte da clínica e, conseqüentemente, inventando novos sentidos de humanidade; Rabinow (1999), por sua vez, considera a influência de diferentes racionalidades médicas na construção das bioidentidades; Ortega (2005) examina os efeitos na corporeidade, no que diz respeito à "antropologia mínima" na fenomenologia do corporal, das novas técnicas de visibilidade do interior do corpo.

Assim, podemos dizer que nos situamos em outra dimensão da história da humanidade, pois, como afirma Foucault, não é mais somente um indivíduo ou sua descendência imediata que é afetada com as intervenções médicas e biológicas, mas a própria vida. Aí, a separação entre natureza e cultura se dissolve; natureza e cultura se fundem; encontramos-nos na dimensão de uma bio-história. Nesse sentido, segundo Rabinow (1999), diz respeito ao fato de a vida se tornar artificial, podemos dizer, cultural, ao mesmo tempo que a cultura se naturaliza. 


\section{Referências}

CANGUILHEM, G. O normal e o patológico. 4. ed. Rio de Janeiro: Forense Universitária, 1995.

COSTA, J. F. O vestígio e a aura: corpo e consumismo na moral do espetáculo. Rio de Janeiro: Garamond, 2004.

ELIAS, N. O processo civilizador. Rio de Janeiro: Zahar, 1994.

DELEUZE, G. Foucault. Paris: Éd. du Minuit, 1986.

FOUCAULT, M. Bio-histoire et bio-politique: dits et écrits, IV, Paris: Gallimard, 1994b.

. Nascimento da clínica. 4. ed. Rio de Janeiro: Forense Universitária, 1994a.

. As palavras e as coisas. 7. ed. São Paulo: Martins Fontes, 1995.

Le sujet et le pouvoir: dits et écrits, IV. Paris: Gallimard, 1994c.

HARAWAY, D. The cyborg manifesto. Disponível em <http// cyborgmanifesto.org/>. Acesso em: jan. 2006.

KEHL, R. As máquinas falantes. In: NOVAES, A. (Org.). O homem-máquina: a ciência manipula o corpo. São Paulo: Cia. das Letras, 2003. p. 243-259.

LE BRETON, D. Adeus ao corpo In: NOVAES, A. (Org.). O homem-máquina: a ciência manipula o corpo. São Paulo: Cia. das Letras, 2003. p. 123-137.

Anthopologie du corps et modernité. Paris: Puf, 2003.

. O corpo enquanto acessório da presença. Revista Comunicação e Linguagens: corpo, técnica, subjetividade, Lisboa. n. 33, p. 67-81, junho 2004.

MACHADO, R. Ciência e saber: a trajetória da arqueologia de Foucault. 2. ed. Rio de Janeiro: Graal, 1988.

ORTEGA, F. Corpo e tecnologias de visualização médica: entre a fragmentação na cultura do espetáculo e a fenomenologia do corpo vivido. Physis: Revista de Saúde Coletiva. Rio de Janeiro, v. 15, n. 2, p. 237-257, 2005 a.

. Fenomenologia da visceralidade: notas sobre o impacto das tecnologias de visualização médica na corporeidade. Cadernos de Saúde Pública, Rio de Janeiro, v. 21, n. 6, p. 1.875-1.883, nov.-dez. 2005b. 
PINELL, P. Médicalisation et procès de civilisation. In: AÏACH, P.; DELANOË, D. (Orgs.). L'ère de la médicalisation: ecc homo sanitas. Paris: Econômica, 1998. p. 37-51.

RABINOW, P. Antropologia da razão. Rio de Janeiro: Relume Dumará,1999.

REID, R. Corps clinique, corps génétique. In: FOUCAULT, M. Lire l'oeuvre. Grenoble: J. Millon, 1992. p. 117-126.

RICOEUR, P. Indivíduo e identidade pessoal. In: VEYNE, P. et al. Indivíduo e poder. Lisboa: Edições 70, 1988. p. 65-85.

SINDING, C. La méthode de la clinique. In: FOUCAULT, M. Lire l'oeuvre. Grenoble: J. Millon, 1992. p. 59-81.

TUCHERMAN, I. Fabricando corpos: ficção e tecnologia. Revista Comunicação e Linguagens: corpo, técnica, subjetividade, Lisboa, n. 33, p. 187-198, junho 2004.

VERNANT, J.-P. O indivíduo na cidade. In: VEYNE, P. et al. Indivíduo e poder. Lisboa: Edições 70, 1988. p. 25-44.

\section{NOTA}

* Professora no Programa de Mestrado em Psicologia da Universidade de Fortaleza; doutora em Saúde Coletiva pelo IMS-UERJ; mestre em Psicologia Clínica pela PUCAMP. Endereço eletrônico: claravirginia@unifor.br. 


\section{ABSTRACT}

\section{Knowledge and medical practice and the constitution of personal identity}

This paper aims to examine the relationship between health practices and the constitution of personal identity. Our starting point is Foucault's theory which states that modern medicine inaugurates a field of scientific knowledge on the body, considering its objectification based on the reference to death. This central part of the body in the medical realm allows the way the subject relates to itself, in which awareness of itself as singularity, that is, as I myself, is mixed-up with organic individuality. We presuppose that within the clinical context, identity formation is bound to the limits of corporeity. However, due to bio-medicine, the body has become an object of manipulation of the individual, and changes the identity relationship between subjectivity and corporeity. Disembodied, personal identity turns into a frenziedly mobile reality.

Key words: Health practice, personal identity; corporeity; Michel Foucault. 